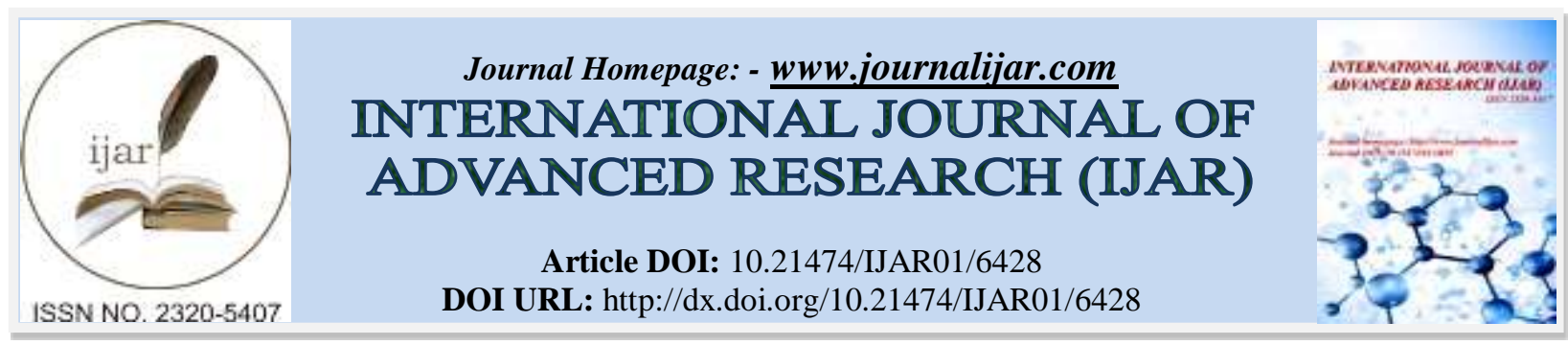

RESEARCH ARTICLE

\title{
SOCIODEMOGRAPHIC PROFILE AND CLINICAL OUTCOME OF OBSTRUCTED LABOUR.
}

Tashaffi Qayoom and Nighat Firdous.

Department of Obstetrics and Gynaecology, Government Medical College, Srinagar, Jammu and Kashmir, India.

\section{Manuscript Info}

Manuscript History

Received: 03 December 2017

Final Accepted: 05 January 2018

Published: February 2018

Key words:-

Apgar score, Caesarean section.

Obstructed labour.

\section{Abstract}

Background: Obstructed labour is the condition that results from failure of descent of the fetal presenting part in the birth canal for mechanical reasons inspite of good uterine contractions. It remains an important cause of maternal and perinatal morbidity and mortality in developing countries.

Materials and Methods: A hospital based cross sectional study was conducted over a period of one and a half years in which 120 cases of obstructed labour were evaluated after applying preselected inclusion and exclusion criteria. Detailed history including that of sociodemographic profile, medical history and obstetric history was taken from every patient. Maternal outcome in the form of mode of delivery and complications was noted. Fetal condition was also evaluated.

Results: The study revealed that obstructed labour was common in illiterate women mostly from rural areas $(87.5 \%)$ of low socioeconomic status $(88.4 \%)$. Majority were primigravidas $(49.2 \%)$ with mean age $30.5 \pm 3.29$. Most cases were due to cephalopelvic disproportion $(62.5 \%)$. Majority were delivered by caesarean section( $87.5 \%)$.The most common complication was abdominal distension(51.7\%) followed by postpartum hemorrhage(37.5\%).There was no maternal death. There were 108 live births $(90 \%)$ out of which $8(7.4 \%)$ died in neonatal period. Obstructed labour was a significant cause of low apgar scores at 5 minutes of birth(34.2\%).

Conclusion: Obstructed labour is still a great contributor of maternal and perinatal mortality in developing world. Sociodemographic and health facility factors were strongly associated with the outcome. Our aim should be universal and inexpensive good obstetric care to avoid it and prompt diagnosis and timely intervention in established cases to improve the outcome.

Copy Right, IJAR, 2018,. All rights reserved.

\section{Introduction:-}

Obstetrics is concerned with the health and wellbeing of both mother and baby. The main aim is to ensure that every pregnancy culminates in a healthy baby with minimal detrimental effects on maternal health. Obstructed labour remains an important cause of maternal and perinatal morbidity and mortality in developing countries despite significant improvement in healthcare facilities. 
Obstructed labour is defined as the condition that results from failure of descent of fetal presenting part in the birth canal despite adequate uterine contractions ${ }^{1}$. Additional features include prolonged labour, hypertonic uterine contractions, bandl's ring $^{2}$ (pathological retraction ring between upper and lower segment), signs of maternal exhaustion, excessive moulding ${ }^{3,4}$ of fetal head, caput succedaneum ${ }^{5}$, vulval edema and clinical signs of shock. The estimated prevalence is 1 to $2 \%$ in developing countries. Causes include ${ }^{6}$ :

A) MATERNAL: 1) Bony causes like contracted pelvis and cephalopelvic disproportion.

2) Soft tissue causes like cervical fibroid, impacted ovarian tumour ,non-gravid horn of bicornuate uterus below presenting part.

B) FETAL:1) Malpresentations and malpostions of fetus:

a) Transverse lie

b) Brow presentation

c) Compound presentation

d) Occipitoposterior position

2) Congenital malformations of fetus:

a) Hydrocephalus

b) Fetal ascites

c) Big baby

d) Locked twins

Several studies have been conducted regarding obstructed labour. In majority of studies lower segment caesarean section (LSCS) was the common mode of delivery. The perioperative complications included abdominal distension, postpartum hemorrhage, perineal injuries, sepsis, uterine rupture and urinary tract injuries. It is also a significant contributor to stillbirths and neonatal mortality.

The aim of this study was to evaluate maternal and perinatal outcome in obstructed labour with an effort to determine predisposing factors.

\section{Materials \& Methods:-}

This cross- sectional study was conducted in LD Hospital, Department of Gynaecology and Obstetrics, Government Medical College, Srinagar, Kashmir over a period of one and half years from February 2015 to August 2016 which is the main tertiary care obstetric hospital of Kashmir.

\section{Sample size:}

120 cases of obstructed labour were selected.

Inclusion criteria were:

1 Term pregnancy.

2 Singleton live pregnancy.

3 Maternal age $20-35$ years.

4 Primigravida to gravida 5.

Exclusion criteria were :

1 Preterm pregnancies .

2 Multiple pregnancies.

3 Previous caesarean section or hysterotomies.

4 Maternal medical disorders.

5 History of substance abuse or addiction.

\section{Methodology:-}

The information collected included obstetric history, sociodemographic history, medical and surgical history of the patient. General condition of the patient was noted with detailed clinical examination. Appropriate management was done and the details thereof of the mode of delivery and associated complications were noted. All patients were followed upto six weeks in postpartum period. Fetal condition was evaluated in terms of occurrence of asphyxia, number of live and stillbirths and neonatal deaths. Apgar score at 5 minutes of less than 4 was taken as birth asphyxia ${ }^{7}$. 


\section{Data Analysis:-}

Continuous variables were summarized as mean+ standard deviation . Categorical variables were summarized as percentages.

\section{Results:-}

About 120 cases of obstructed labour were studied. The mean age was $30.5 \pm 3.29$ in years(table 1). Cephalopelvic disproportion was the most common cause in $62.5 \%$ followed by malpresenations of fetus in $30.8 \%$ and congenital fetal malformations in $6.7 \%$ (table 2). Most of the patients were primigravidas $(49.2 \%$ ) followed by parity more than or equal to 3 in $22.5 \%$ as shown in table 3. Majority (87.5\%) were from rural areas (table 4). Many patients were illiterate $(39.2 \%)$ or had received only primary education $(27.5 \%)$ as depicted in table 5 . Most patients (52.5\%) were unbooked ( table 6) and had no antenatal checkups done ( table 7).64.2\% were of average and $24.2 \%$ of poor socioeconomic status( table 8). Majority ( $87.5 \%$ ) were delivered by LSCS(lower segment caesarean section) followed by forceps in $4.17 \%$, ventouse(vacuum) in $4.17 \%$, laparotomy with repair of uterine rupture in $1.66 \%$, subtotal hysterectomy in $1.66 \%$ and total abdominal hysterectomy in $0.84 \%$ as shown in table 9 . Most common complication was abdominal distension (51.7\%) followed by postpartum hemorrhage in 37.5\% as shown in table 10 . 5 cases $(4.2 \%)$ of rupture uterus were reported. No case of vesicovaginal fistula was seen and there was no maternal death. Mean postpartum hospital stay was $8.9 \pm 2.43$ days ( table 11).

There were 108 livebirths(90\%) and 12 stillbirths (10\%) as depicted in table 12. Neonatal asphyxia and NICU admission was seen in $34.2 \%$ livebirths and neonatal death was seen in $7.4 \%$ as shown in table 13 . Majority of babies $(56.5 \%$ ) has 5 minute apgar score more than or equal to 7 , while $34.2 \%$ had apgar score less than 4 as shown in table 14.

Table 1:- Age distribution of study population

\begin{tabular}{|l|l|l|}
\hline Age (years) & Frequency & Percentage \\
\hline $20-24$ & 3 & 2.5 \\
\hline $25-29$ & 43 & 35.8 \\
\hline $30-34$ & 55 & 45.8 \\
\hline$\geq 35$ & 19 & 15.8 \\
\hline Total & 120 & 100 \\
\hline Mean \pm SD $=30.5 \pm 3.29$ & \multicolumn{2}{|l|}{} \\
\hline
\end{tabular}

Table 2:- Causes of obstructed labour

\begin{tabular}{|l|l|l|}
\hline Cause & Frequency & Percentage \\
\hline Cephalopelvic Disproportion & 75 & 62.5 \\
\hline Malpresentation / Malposition of fetus & 37 & 30.8 \\
\hline Congenital malformations of fetus & 8 & 6.7 \\
\hline
\end{tabular}

Table 3: Showing obstetric history among study population

\begin{tabular}{|l|l|l|}
\hline Parity & Frequency & Percentage \\
\hline 0 (primigravida) & 59 & 49.2 \\
\hline 1 & 18 & 15.0 \\
\hline 2 & 16 & 13.3 \\
\hline$\geq 3$ & 27 & 22.5 \\
\hline Total & 120 & 100 \\
\hline
\end{tabular}

Table 4:- Showing distribution of study population as per residence

\begin{tabular}{|l|l|l|}
\hline Area of residence & Frequency & Percentage \\
\hline Rural & 105 & 87.5 \\
\hline Urban & 15 & 12.5 \\
\hline Total & $\mathbf{1 2 0}$ & $\mathbf{1 0 0}$ \\
\hline
\end{tabular}


Table 5:- Showing educational status of study patients

\begin{tabular}{|l|l|l|}
\hline Educational Status & Frequency & Percentage \\
\hline Illiterate & 47 & 39.2 \\
\hline Primary & 33 & 27.5 \\
\hline SSC & 9 & 7.5 \\
\hline HSC & 18 & 15.0 \\
\hline Graduate & 13 & 10.8 \\
\hline Total & $\mathbf{1 2 0}$ & $\mathbf{1 0 0}$ \\
\hline
\end{tabular}

Table 6:- Distribution of booked / unbooked cases among study population

\begin{tabular}{|l|l|l|}
\hline Parameter & Frequency & Percentage \\
\hline Booked & 57 & 47.5 \\
\hline Unbooked & 63 & 52.5 \\
\hline Total & $\mathbf{1 2 0}$ & $\mathbf{1 0 0}$ \\
\hline
\end{tabular}

Table 7:- Showing antenatal check up among study population

\begin{tabular}{|l|l|l|}
\hline Antenatal check up & Frequency & Percentage \\
\hline Nil & 63 & 52.5 \\
\hline $1-2$ & 28 & 23.3 \\
\hline $3-4$ & 14 & 11.7 \\
\hline $5-6$ & 15 & 12.5 \\
\hline Total & $\mathbf{1 2 0}$ & $\mathbf{1 0 0}$ \\
\hline
\end{tabular}

Table 8:- Showing socio economic status of study population

\begin{tabular}{|l|l|l|}
\hline SE Status & Frequency & Percentage \\
\hline Poor & 29 & 24.2 \\
\hline Average & 77 & 64.2 \\
\hline Good & 14 & 11.7 \\
\hline Total & $\mathbf{1 2 0}$ & $\mathbf{1 0 0}$ \\
\hline
\end{tabular}

Table 9:- Showing mode of delivery among study population

\begin{tabular}{|l|l|l|}
\hline Mode of Delivery & Frequency & Percentage \\
\hline LSCS & 105 & 87.5 \\
\hline Forceps Delivery & 5 & 4.17 \\
\hline Ventouse Delivery & 5 & 4.17 \\
\hline Laparotomy With Repair of Ruptured Uterus & 2 & 1.66 \\
\hline Laparotomy with subtotal hysterectomy & 2 & 1.66 \\
\hline Total Abdominal Hysterectomy & 1 & 0.84 \\
\hline Total & 120 & 100 \\
\hline
\end{tabular}

Table 10:- Distribution of maternal complications among study population

\begin{tabular}{|l|l|l|}
\hline Maternal Complications & Frequency & Percentage \\
\hline Postpartum hemorrhage & 45 & 37.5 \\
\hline Abdominal Distension & 62 & 51.7 \\
\hline Perineal Injuries & 28 & 23.3 \\
\hline Sepsis & 2 & 1.7 \\
\hline Wound Soakage & 27 & 22.5 \\
\hline Urinary Tract Infection & 22 & 18.3 \\
\hline Urinary Tract Injuries & 2 & 1.7 \\
\hline Burst Abdomen & 2 & 1.7 \\
\hline Rupture Uterus & 5 & 4.2 \\
\hline Vesicovaginal Fistula & 0 & 0.0 \\
\hline Maternal Death & 0 & 0.0 \\
\hline
\end{tabular}


Table 11:- Showing postpartum hospital stay among study population

\begin{tabular}{|l|l|l|}
\hline Postpartum Hospital Stay (Days) & Frequency & Percentage \\
\hline$\leq 7$ Days & 18 & 15.0 \\
\hline 8-10 Days & 87 & 72.5 \\
\hline$>10$ Days & 15 & 12.5 \\
\hline Total & 120 & 100 \\
\hline Mean \pm SD $=8.9 \pm 2.43$ & \\
\hline
\end{tabular}

There were 108 livebirths (90\%) as shown in table 12. Neonatal asphyxia was seen in $34.2 \%$ patients. Neonatal death was seen in 7.4\% patients as depicted in table 13. As shown in table 14 majority of babies had 5 minute Apgar score more than or equal to 7 .

Table 12:- Distribution of fetal condition during birth among study population

\begin{tabular}{|l|l|l|}
\hline Fetal Condition & Frequency & Percentage \\
\hline Live Birth & 108 & 90 \\
\hline Still Birth & 12 & 10 \\
\hline Total & $\mathbf{1 2 0}$ & $\mathbf{1 0 0}$ \\
\hline
\end{tabular}

Table 13:- Distribution of perinatal complications among the live birth [ $\mathrm{n}=108]$

\begin{tabular}{|l|l|l|}
\hline Perinatal Complications & Frequency & Percentage \\
\hline Neonatal Asphyxia & 37 & 34.2 \\
\hline NICU Admission & 37 & 34.2 \\
\hline Neonatal Death & 8 & 7.4 \\
\hline
\end{tabular}

Table 14:- Apgar Score at 5 Minutes Among Live born (108)

\begin{tabular}{|l|l|l|}
\hline APGAR SCORE & Frequency & Percentage \\
\hline$<4$ & 37 & 34.2 \\
\hline $4-6$ & 10 & 9.3 \\
\hline$>=7$ & 61 & 56.5 \\
\hline
\end{tabular}

\section{Discussion:-}

In our study the mean age reported was $30.5+3.29$ close to that reported by Amaneul et al $(2003)^{8} 28.8 \pm 7.6$ with the difference being explained by rising incidence of elderly primigravidas in this part of the world. Most cases were due to cephalopelvic disproportion (62.5\%). This was comparable to the study of Saad E Dafallah et al (2003) ${ }^{9}$ where $57 \%$ cases were due to this cause. Majority of the patients were primigravidas (49.2\%) comparable to the study of Anjum Ara (1996) ${ }^{10}$ where $40.8 \%$ patients of obstructed labour were primigravidas. Majority were from rural areas $(87.5 \%)$ comparable to the findings of Islam JA et al 2012$)^{11}$ who reported $88 \%$ from rural areas. Majority were either illiterate or with only primary education (66.7\%) comparable to highest incidence in low education patients $(87 \%)$ in the study of Islam JA et al (2012) ${ }^{11}$. Most patients were unbooked (52.5\%) comparable to $63.8 \%$ in the study of Saad E Dafallah et al (2003) ${ }^{9}$. Majority of patients were of poor to average class $(88.4 \%)$ comparable to earlier study of Islam JA et al ( 2012) ${ }^{11}$ where majority $(93.3 \%)$ were of the same class.

In our study, $87.5 \%$ patients were delivered by LSCS, $4.17 \%$ by forceps, $4.17 \%$ by ventouse. 2 patients (1.66\%) had laparotomy with repair of uterine rupture and 2 more had subtotal hysterectomy.1 patient $(0.84 \%)$ had total abdominal hysterectomy. Konje et al $(1992)^{12}$ reported caesarean section rate of $82 \%$. Shahneela et al( 2009$)^{13}$ reported caesarean section in $81.1 \%$ cases of obstructed labour. The higher incidence of caesarean section in this study is explained by virtual non occurrence of destructive operations at our centre in view of high maternal and fetal morbidity associated with them.

In our study ,the most common complication in these patients was abdominal distension in $51.7 \%$ followed by postpartum hemorrhage in 37.5\% patients.23.3\% had some degree of perineal injuries.18.3\% had mild to severe urinary tract infections. $1.7 \%$ had urinary tract injuries during abdominal surgery.5 patients( $4.2 \%)$ had rupture uterus out of which 2 (1.66\% underwent laparotomy with repair of uterine rupture, $2(1.66 \%)$ required subtotal hysterectomy and $1(0.84 \%)$ underwent total abdominal hysterectomy. No maternal death was seen .These findings 
were comparable to earlier studies like that of Islam JA et al (2012) ${ }^{11}$ who reported abdominal distension as the most common complication followed by sepsis in $14.3 \%$ and postpartum hemorrhage in $9.6 \%$ cases.

No case of vesicovaginal fistula was reported over a period of six weeks due to prophylactic bladder catheterization for 7 to 10 days in these patients.

Most patients had postpartum hospital stay of 8 to 10 days(72.5\%).J Wanyoike et al ( 2015) ${ }^{14}$ in his study reported majority of these patients with a postpartum hospital stay of 8 to 14 days $(46.7 \%)$.

In our study there were $108(90 \%)$ live births and 12(10\%) still births. J Wanyoike et al (2015) ${ }^{14}$ reported $81.5 \%$ live births.

In our study 37 out of 108 live born babies (34.2\%) had an Apgar score < 4 at 5 minutes of birth comparable to the study of Islam JA et al (2012) ${ }^{11}$ who reported $33.3 \%$ babies with Apgar scores $<4$ at 5 minutes of birth. All of these babies with neonatal asphyxia were admitted in Neonatal ICU(NICU) . Ritu Gupta et al ( 2012) ${ }^{15}$ reported NICU admission rate of $55.7 \%$ in their study.

8 babies(7.4\%) died in neonatal period comparable to the study of Anjum Ara et al(1996) ${ }^{10}$ where $7 \%$ babies born to mothers with obstructed labour died in the neonatal period.

\section{Conclusion:-}

Obstructed labour is one of the main contributors to maternal and fetal morbidity and mortality in developing countries. Improvement in socioeconomic conditions and health education along with timely and proper intervention can help to a great extent in reducing the burden it poses on health system.

Funding: No funding sources.

Conflict of interest: None declared

Ethical approval: The study was approved by the Institutional Ethical Committee.

\section{References:-}

1. Neilson JP, Lavender T,Quenby S, Wray S. Obstructed Labour.Br Med Bull 2003;67:191-204.

2. Renu Misra, Aruna Yerra. Obstructed labour. Ian Donald's Practical Obstetric Problems, seventh edition, pg 593.

3. Carlan SJ, Wyble L, Lense J et al. Fetal head moulding: diagnosis by ultrasound and a review of literature. J Perinatol 1991;11:105.

4. Graham JM Jr, Kumar A. Diagnosis and management of extensive birth molding, Clin Pediatr ( Phila) 2006;45(7):672.

5. Williams Obstetrics, $24^{\text {th }}$ edition , caput succedaneum. Chapter 22. Page 444.

6. DC Dutta Textbook of Obstetrics, seventh edition, chapter 26, page 404, obstructed labour.

7. Brian M Casey, Donald D. Mcintire, Kenneth J Leveno. The continuing value of Apgar Score for assessment of newborn infants. N Engl J Med 2001; 344: 467-471.

8. Amaneul Gessessew, Mengiste Mesfin. Obstructed labour in Adigrat Zonal Hospital, Ethiopia. Ethiop .J. Health Dev 2003; 17(3): 175- 180.

9. Saad E Dafallah ,Justin Ambago, Faroug El Agib. Obstructed labour in teaching hospital in Sudan. Saudi Med J 2003; Vol . 24(10):1102-1104.

10. Anjum Ara. Outcome of obstructed labour. JPMI 1996; Vol. 18(3).

11. Islam JA, Ara G, Choudhry FR. Risk factors and Obstructed labour at a Tertiary care Hospital .J Shaheed Suhrawardy Med Coll. 2012;4(2):43-46.

12. Konje JC, Obisesan KA, Ladipo OA. Obstructed labour in Ibadan. Int J Gynaecol 1992 Sep ;39(1):17-21.

13. Shahneela Memon, Roshan Ara Qazi, Pushpa and Imdad A. Khushk. Pattern of obstructed labour at a public sector University Hospital of Sindh, Pakistan .JLUMHS January - April 2009;Vol 08, No 1:60-64.

14. J Wanyoike Gichuhi, Soita M, Kiragu JM . Pregnancy outcome in women with obstructed labour in a rural hospital, Kenya. European International Journal of Science and Technology.2015 Feb ; Vol 4, No. 2.

15. Ritu Gupta, Sanjay Kumar Porwal. Obstructed Labour: Incidence, causes and outcome. Int J Biol Med Res 2012;3(3): 2185-2188. 